\title{
Responsabilidad de los centros de arbitraje en Ecuador
}

\author{
Natalia Ordóñez Rivera* \\ Recibido/Received: 23/07/2018 \\ Aceptado/Accepted: 26/07/2018
}

SumARIO: 1. Introducción. 2. El Contrato de Administración de Arbitraje (CAA). 3. Responsabilidad contractual de la institución arbitral bajo el CAA. 4. Las funciones jurisdiccionales de los directores de los centros de arbitraje. 5. La responsabilidad del director del centro en ejercicio de sus funciones jurisdiccionales. 5.1 Retardo injustificado. 5.2 Negligencia. 5.3 Denegación de justicia. 5.4 Quebrantamiento de ley. 6. Conclusiones.

Palabras Clave: arbitraje institucional, arbitraje administrado, responsabilidad civil, responsabilidad judicial, indemnización de daños y perjuicios.

KEYWORDS: institutional arbitration, liabilities, judicial responsibility, damages.

RESUMEN: El presente trabajo busca determinar el régimen jurídico aplicable a la responsabilidad de los centros de arbitraje de Ecuador en el ejercicio de sus funciones, desde una perspectiva contractual, para el centro de arbitraje en sus funciones administrativas, y extracontractual para el director del centro en el ejercicio de ciertas funciones de carácter jurisdiccional.

* Analista de Contratos para el Legal Support Center de Schlumberger en Bogotá, Colombia. Abogada por la Universidad San Francisco de Quito. Correo electrónico: natalia.ordonez22@gmail.com

N. ORDÓÑEz RIVERA, "Responsabilidad de los Centros de Arbitraje en Ecuador”, Revista Ecuatoriana de Arbitraje, No. 9, 2017. 


\begin{abstract}
AвSTRACT: The purpose of this article is to determine the nature of the arbitral institution's liability in Ecuador for the provision of their services, with two different perspectives: the liability seen as contractual for the performance of administrative tasks by the arbitral institution, and then extra contractual for the performance of jurisdictional attributions by the director of the arbitral institution.
\end{abstract}

\title{
1. INTRODUCCIÓN
}

Cuando las partes deciden someter sus controversias a arbitraje tienen dos posibilidades, que el arbitraje sea administrado o independiente. Si la opción elegida es que sea administrado, interviene un sujeto adicional en el proceso para la resolución de la disputa: la institución arbitral encargada de administrar la controversia.

Es en este supuesto en el que surge una duda, ¿cuál es la naturaleza jurídica de la relación que poseen los suscriptores del convenio arbitral y el centro de arbitraje? ¿Es posible hacer un reclamo de daños y perjuicios a un centro de arbitraje por la administración de un procedimiento?

En este artículo analizaremos que sí es posible realizar un reclamo de daños y perjuicios a una institución arbitral porque existe una relación contractual que se sustenta en que ambas partes han llegado a un acuerdo para crear obligaciones, el centro estará obligado a administrar la controversia y las partes del convenio arbitral pagarán este servicio. No vamos a analizar el hecho de que el reclamo debe necesariamente venir aparejado de la solicitud de cumplimiento o la resolución del contrato, pues como a todo contrato, las reglas del Código Civil le son aplicables. A este acuerdo lo llamaremos Contrato de Administración de Arbitraje (en adelante, CAA). 
Sin embargo, existen ciertas actuaciones del director del centro que son de naturaleza jurisdiccional y, por tanto, escapan al régimen contractual. Esta responsabilidad sería de la misma naturaleza que la de los jueces y árbitros; es decir, sería extracontractual. El fundamento de esta posición es que, en los procesos judiciales bajo la justicia ordinaria, las diligencias de calificación a la demanda, citación, notificación y resolución de la recusación son responsabilidad de los jueces. En el arbitraje administrado, la práctica de estas diligencias es responsabilidad de los directores del centro de arbitraje, por lo tanto, concluimos que desempeñan funciones jurisdiccionales.

\section{El Contrato de Administración de Arbitraje (CCA)}

"[T]he relationship between the parties to arbitration and the arbitral institution administering the arbitration is generally considered to be contractual"1. El CAA cumple todas las características para ser considerado contrato porque es un acuerdo de voluntades en virtud del cual dos o más partes se obligan a acudir a determinada institución arbitral para la administración de su arbitraje. El CAA posee todos los requisitos de existencia de un negocio jurídico que son el consentimiento ${ }^{2}$, el objeto y la causa ${ }^{3}$.

Respecto del consentimiento, "es el acuerdo de dos o de muchas personas en el contrato proyectado, la resultante de las voluntades que se unen" ${ }^{4}$. Éste constituye la sustancia misma del negocio jurídico, y en nuestro caso, del contrato ${ }^{5}$. Para que el consentimiento sea suficiente para crear obligaciones es necesario

1. "La relación entre las partes del arbitraje y la institución arbitral que administra el arbitraje generalmente se considera contractual". Traducción libre. N. BLACKABY et al., Redfern and Hunter on International Arbitration. 5ta Ed., Oxford University Press, 2009, p. 332.

2. A. Vodanovic, Derecho Civil. Parte Preliminar y Parte General, Tomo II, Ediar, 1991 p. 181.

3. Se discute si es que la causa es un requisito de existencia de los negocios jurídicos. OsPINA FernándeZ sostiene que no, véase, G. Ospina Fernández, Teoría General del Contrato y del Negocio Jurídico, Editorial Temis S.A., 2000, p. 28.

4. L. Claro Solar, Explicaciones de Derecho Civil Chileno y Comparado, Tomo XI, Editorial Jurídica Chile, 1992, p. 54.

5. G. OSPINA FernÁNdeZ, N. 3, p. 28. 
que la voluntad sea seria y exteriorizada, y así produzca efectos jurídicos ${ }^{6}$. Es seria aquella que tiene el propósito de vincular a quien lo manifiesta y exteriorizada aquella que se proyecta ya sea expresa o tácitamente ${ }^{7}$. La forma en que se perfecciona este consentimiento es a través de una oferta y una aceptación ${ }^{8}$, tal como lo prescribe el artículo 141 del Código de Comercio 9 .

En nuestro caso, la oferta para el CAA se realiza a través del reglamento del centro, que es permanente en el tiempo ${ }^{10}$. Se trata de una oferta porque es una propuesta de contrato que la institución realiza a las partes ${ }^{11}$ y cumple todos los requisitos para ser vinculante: es seria, libre y completa ${ }^{12}$.

Una oferta es seria si el oferente busca obligarse a través de ella, es decir, tiene la voluntad de celebrar un negocio jurídico futuro $^{13}$. Precisamente, los centros ofrecen sus servicios con la intención de que los particulares los seleccionen en sus convenios arbitrales.

Además, se trata de una oferta completa pues posee todos los elementos necesarios para que el futuro contrato se perfeccione con la simple aceptación de las partes ${ }^{14}$. Dentro del reglamento se encuentran detallados todos los aspectos respecto del arbitraje, incluidas las tarifas del centro ${ }^{15}$.

6. A. VodANOVic, N. 2, p. 181.

7. Ídem, pp. 182 y 183.

8. J. Martínez Alarcón, Teoría General de las Obligaciones, 2da Ed., Oxford University Press, 2000, p. 34.

9. Código de Comercio, Art. 141, RO Sup. No. 1202, 20/08/1960.

10. J. M. Roca Martínez, Arbitraje e Instituciones Arbitrales, José María Bosch, 1992, p. 225.

11. M. Albaladejo, Derecho Civil. Derecho de Obligaciones, 9na Ed., Vol. 1, José María Bosch, 1994, p. 367.

12. R. Pinochet Olave, "La Formación del Consentimiento a Través de las Nuevas Tecnologías de la Información. Parte I: La Oferta Electrónica”, Ius et praxis, No. 10-2, 2004, pp. 24 y 25.

13. Ídem, p. 24.

14. Véase, M. Albaladejo, N. 11, p. 369; A.G. Spota, Contratos. Instituciones de Derecho Civil. 2 da Ed., Tomo I, La Ley, 2009, p. 482.

15. Véase, Reglamento General del Centro de Arbitraje y Conciliación de la Cámara de Comercio de Guayaquil (en adelante, Reglamento CCG), 13/06/2013; Reglamento del Centro de Arbitraje y Mediación de la Cámara de Comercio de Ecuatoriano Americana (en adelante, Reglamento AMCHAM), 26/10/2010; Codificación del Reglamento para el Funcionamiento del Centro de Arbitraje y Mediación de la Cámara de Comercio De Quito (en adelante, Reglamento CCQ), 21/07/2011. 
Finalmente, es una oferta que se encuentra dirigida al público $^{16}$. Se trata de una policitación, según el artículo 148 del Código de Comercio:

Las ofertas públicas contenidas en circulares, catálogos, avisos publicitarios, proformas, obligan a quien las hace; salvo que en la misma oferta se señale un determinado plazo de validez de la misma o que las condiciones de la oferta original sean modificadas por una oferta posterior ${ }^{17}$.

En su oferta, el centro describe el servicio que presta e invita a los usuarios a emplear sus cláusulas modelo para que puedan aprovecharlo. De esta forma es claro que estamos frente a una oferta pública vinculante para los centros.

Por su parte, la aceptación se produce cuando cualquiera de los suscriptores del convenio arbitral presenta la demanda ante el centro. Esta aceptación debe ser llana, es decir, no debe estar sujeta a ninguna condición ni modalidad, pues de lo contrario, es una contraoferta ${ }^{18}$ y solo surte efectos jurídicos cuando es notificada a la otra parte ${ }^{19}$.

Todo lo explicado ha sido sostenido también por los profesores GAILlARD y SAVAGE:

By drafting and publishing its arbitration rules the arbitral institution effectively puts out a permanent offer to contract, aimed at an indeterminate group of persons [...] but made under fixed conditions. By concluding the arbitration agreement, the parties accept that offer and agree to empower their chosen institution to organize and oversee the arbitration in the event that a dispute arises between them [...]. When the request for arbitration is submitted to the institution and it begins to organize the proceedings, the contract is perfected. Generally, it will not be perfected before that point, because the institution will not know whether its offer has been accepted ${ }^{20}$.

16. M. Albaladejo, N. 11, p. 367.

17. Código de Comercio, N. 9, Art. 148.

18. G. A Borda, Manual de Contratos, 18va Ed., Editorial Perrot, 1998, p. 46.

19. M. Furmston, T. Norisada y J. Poole, Contract Formation and Letters of Intent, John Wiley \& Sons Ltd., 1998, p. 34.

20. "Al redactar y publicar sus reglas de arbitraje, la institución arbitral realiza una oferta permanente de 
Si la aceptación no se da de una forma clara, corresponderá al tribunal arbitral decidir si existen los suficientes elementos para declararse competente. Si considera que sí, entonces también existe un contrato entre el centro y las partes, pero si considera que no, el CAA no se perfeccionó.

El segundo requisito de existencia de un negocio jurídico es el objeto. "El objeto de los contratos es la prestación prometida por las partes"21. Asimismo, "[e]l objeto del contrato son los derechos que él crea y no las cosas que se trata de dar, hacer o no hacer" 22 . Por esto, el objeto del CAA está conformado por los derechos y obligaciones creados mediante este contrato. Las partes tienen el derecho de que la institución arbitral administre el arbitraje mientras que la institución tiene el derecho a recibir el pago por sus servicios. Estas dos obligaciones/derechos pueden ser descompuestas en varias prestaciones.

Respecto de la obligación de la institución arbitral de administrar el arbitraje, podemos encontrar que la Ley de Arbitraje y Mediación (en adelante, LAM) les obliga a: enviar la lista de árbitros del centro para que las partes los designen ${ }^{23}$, realicen un sorteo en caso de imposibilidad de selección de árbitros por las partes $^{24}$, realizar la convocatoria para la posesión de los árbitros ${ }^{25}$, posesión de los árbitros frente al presidente del centro ${ }^{26}$, contar con elementos administrativos y técnicos necesarios para la conducción de los arbitrajes ${ }^{27}$, guardar confidencialidad cuando las partes así lo hayan dispuesto ${ }^{28}$, entre otras.

contrato, dirigida a un grupo indeterminado de personas [...] pero con condiciones fijas. Al suscribir el convenio arbitral, las partes aceptan esa oferta y designan a la institución para organizar y supervisar el arbitraje en caso de que surja una disputa entre ellas [...]. Cuando la solicitud de arbitraje se presenta a la institución, el contrato se perfecciona. Generalmente, no se perfeccionará antes de ese punto, porque la institución no sabría que su oferta ha sido aceptada.” Traducción libre. E. GAILLARD y J. SAVAGE, Fouchard Gaillard Goldman on International Commercial Arbitration, Kluwer International, 1999 , p. 602.

21. G. A Borda, N. 18 , p. 82.

22. P. Rodríguez Grez, Responsabilidad Contractual, Editorial Jurídica de Chile, 2012, p. 90.

23. Ley de Arbitraje y Mediación (LAM), Art. 16, RO No. 417, 14/12/2006.

24. LAM, N. 23, Art. 16.

25. LAM, N. 23, Art. 17.

26. LAM, N. 23, Art. 17.

27. LAM, N. 23, Art. 39.

28. LAM, N. 23, Art. 34. 
Además, las instituciones arbitrales tienen reglamentos de funcionamiento. Dentro de éstos, también se incluyen disposiciones que regirán la relación contractual, pues la oferta de arbitraje de los centros está detallada en su reglamento, tal como mencionamos anteriormente. Estos reglamentos recogen las mismas obligaciones de la ley, pero adicionalmente poseen otras normas. Por ejemplo, archivar laudos y para la consulta y la expedición de copias certificadas ${ }^{29}$, la forma de hacer notificaciones y citaciones ${ }^{30}$, entre otras.

Por su parte, las obligaciones de las partes frente al centro son las siguientes: adjuntar a los escritos cuantas copias sean necesarias para todos quienes intervienen en el proceso ${ }^{31}$, cumplir todas las disposiciones del reglamento ${ }^{32}$, asumir los costos del traslado y viáticos del tribunal arbitral cuando soliciten que se constituya en otro sitio que no sea el centro ${ }^{33}$, cubrir los costos de las traducciones que se hagan cuando las partes pacten otro idioma para el arbitraje diferente del castellano ${ }^{34}$, pagar los costos del servicio prestado por la institución arbitral ${ }^{35}$, realizar el pago de la totalidad del arbitraje por parte del actor al momento de presentar la demanda ${ }^{36}$, entre otras.

El último requisito de existencia es la causa. "La causa del contrato es [...] el motivo que induce a él, esto es, la fuerza que impulsa a la voluntad a contratar"37. "La causa de la obligación de una de las partes en el contrato bilateral es la obligación correlativa de la otra parte" 138 .

La nota característica del contrato bilateral es la reciprocidad de las obligaciones que de él derivan. Así pertenecen a esta clase la compraventa y la sociedad, porque cada uno de los

29. Reglamento CCQ, N. 15, Art. 3(f).

30. Reglamento AMCHAM, N. 15, Art. 45; Reglamento CCQ, N. 15, Art. 51.

31. Reglamento AMCHAM, N. 15, Art. 47; Reglamento CCQ, N. 15, Art. 54.

32. Reglamento AMCHAM, N. 15, Art. 48; Reglamento CCQ, N. 15, Art. 55.

33. Reglamento AMCHAM, N. 15, Art. 49; Reglamento CCQ, N. 15, Art. 56.

34. Reglamento AMCHAM, N. 15, Art. 53; Reglamento CCQ, N. 15, Art. 60.

35. Reglamento AMCHAM, N. 15, Art. 67; Reglamento CCQ, N. 15, Art. 70.

36. Reglamento AMCHAM, N. 15, Art. 69. Reglamento CCQ, N. 15, Art. 71.

37. P. Rodríguez Grez, N. 22, p. 101.

38. V. Vial Del Río, Teoría general del acto jurídico, Editorial Jurídica de Chile, 2011, p. 192. 
agentes o partes que en ellas intervienen, desempeña, a la vez, los papeles de deudora y de acreedora de la otra $u$ otras. Es de notar que en estos contratos las partes pueden ser más de dos, como sucede en la sociedad, que se puede formar entre muchos socios, y que, por consiguiente, el calificativo bilateral, consagrado por el uso en vez de plurilateral, resulta impropio ${ }^{39}$.

Así, aunque se trate de un contrato plurilateral, el CAA tiene por causa la obligación correlativa de cada parte.

\section{RESPONSABILIDAD CONTRACTUAL DE LA INSTITUCIÓN ARBITRAL BAJO EL CAA}

Como ya hemos explicado, la relación entre las partes y el centro cumple los requisitos necesarios para ser considerada contractual. Esto sin duda trae aparejadas una serie de consecuencias, como la aplicación del principio pacta sunt servanda ${ }^{40} \mathrm{o}$ la buena fe contractual ${ }^{41}$ o como el hecho de que la institución arbitral puede ser encontrada responsable civilmente por algún incumplimiento contractual y ser obligada a indemnizar. Así también, como todo acreedor ${ }^{42}$, los suscriptores del convenio arbitral tienen derecho a exigir la ejecución forzosa de las obligaciones de la institución y viceversa.

Es común encontrar dentro de algunos de los reglamentos de las instituciones arbitrales normas que establecen la no responsabilidad de los centros en los arbitrajes. Por ejemplo, el Art. 14 del Reglamento General del Centro de Arbitraje y Conciliación de la Cámara de Comercio de Guayaquil establece:

La Cámara de Comercio de Guayaquil y el Centro de Arbitraje y Conciliación no asumen ningún tipo de responsabilidad por los perjuicios que por acción y omisión, en ejercicio de sus fun-

39. G. Ospina Fernández, N. 3, p. 59.

40. Código Civil, Art. 1561, RO Sup. No. 46, 24/05/2005.

41. Código Civil, N. 40, Art. 1562.

42. M. Planiol, y G. RiPert, Tratado Elemental de Derecho Civil, Tomo IV, Cardenas Editor y Distribuidor, 1991, pp. 123 y 124. 
ciones, los conciliadores, árbitros y secretarios ocasionen a las partes o a terceros ${ }^{43}$.

Lo mismo encontramos en el Art. 18 del Reglamento del Centro de Arbitraje y Mediación de la Cámara de Comercio de Ecuatoriano Americana.

La Cámara de Comercio Ecuatoriano Americana, el Centro de Arbitraje y Mediación y sus administradores, no asumen ningún tipo de responsabilidad por los perjuicios que por acción u omisión, en ejercicio de sus funciones, los árbitros, mediadores, secretarios arbitrales, peritos o negociadores ocasionaren a las partes o a terceros ${ }^{44}$.

Una disposición similar se encuentra en el Art. 21 de la Codificación del Reglamento para el Funcionamiento del Centro de Arbitraje y Mediación de la Cámara de Comercio de Quito.

La Cámara de Comercio de Quito y el Centro de Arbitraje y Mediación no asumen ningún tipo de responsabilidad por los perjuicios que por acción u omisión, en ejercicio de sus funciones los mediadores, árbitros, secretarios y peritos ocasionen a las partes o a terceros. ${ }^{45}$

Estas cláusulas están solamente encaminadas a exonerar de responsabilidad en las funciones ejercidas por árbitros, mediadores, secretarios arbitrales, peritos, entre otros, pero no eximen a la institución arbitral de la responsabilidad por el incumplimiento de sus propias obligaciones.

Sobre las cláusulas de exoneración de responsabilidad en los reglamentos arbitrales, los profesores GAILLARD y SAVAGE han comentado que su validez es discutible por encontrarnos en un contrato de adhesión.

43. Reglamento CCG, N. 15, Art. 14.

44. Reglamento AMCHAM, N. 15, Art. 18.

45. Reglamento CCQ, N. 15, Art. 21. 
Some institutions protect themselves further by including in their rules a clause excluding their liability. This is the case of the ICC, which introduced the following provision at Article 34 of its 1988 Rules:

"Neither the arbitrators, nor the Court and its members, nor the ICC and its employees, nor the ICC National Comitees, shall be liable to any person for any act or omission in connection with the arbitration".

It is not certain that these provisions enhance the institution's appeal to its users. Further, it may well be that the courts hold that such clauses to be ineffective in the case of gross fault by the institution or, in certain cases, abusive or unconscionable conduct, given, in particular, that such clauses are contained in a contract of adhe$\operatorname{sion}^{46}$.

La cláusula de exoneración de responsabilidad debe ser analizada caso por caso, para determinar si exime de responsabilidad a la institución o no. Para casos de incumplimientos exclusivos de la institución arbitral, esta cláusula no tiene aplicación alguna pues solamente está redactada para eximir al centro de responsabilidad por los daños ocasionados por árbitros, peritos, secretarios y mediadores.

Finalmente, "la cláusula de no responsabilidad no llega jamás a suprimir la responsabilidad de su beneficiario culpable de dolo"47. Así, aunque la cláusula no es eficiente para lograr una exención de responsabilidad para el centro por sus incumplimientos, no se puede pactar una cláusula que sí lo haga en todos los casos, porque el dolo no puede ser condonado, solo la culpa. Tampoco se admite la culpa lata porque ésta es equiparable al dolo $^{48}$.

46. “Algunas instituciones se protegen aún más al incluir en sus reglas una cláusula que excluye su responsabilidad. Este es el caso de la CCI, que introdujo la siguiente disposición en el Artículo 34 de sus Reglas de 1988: 'Ni los árbitros, ni el Tribunal y sus miembros, ni la CCI, sus empleados, ni los Comités Nacionales de CCI, serán responsables ante ninguna persona por ningún acto u omisión en relación con el arbitraje'. Es incierto que estas disposiciones aumenten el atractivo de la institución para sus usuarios. Además, es posible que los tribunales sostengan que tales cláusulas son ineficaces en caso de negligencia grave por parte de la institución o, en ciertos casos, conductas abusivas o desmesuradas, dado, en particular, que tales cláusulas están contenidas en un contrato de adhesión". Traducción libre. E. Gaillard y J. SaVage, N. 20, p. 603.

47. L. Claro Solar, N. 4, p. 548.

48. Ídem, p. 551. 


\section{LAS FUNCIONES JURISDICCIONALES DE LOS DIRECTORES de los Centros de Arbitraje}

En nuestro ordenamiento jurídico se ha declarado que el arbitraje es un servicio público. De acuerdo con la teoría jurisdiccional del arbitraje, el Estado autoriza la existencia de arbitrajes y otros métodos alternativos de resolución de disputas. "Esta autorización (vía el concepto de arbitrabilidad) es un acto de justicia delegada, o paralela, que encuentra su sanción en la ejecutabilidad del laudo en forma similar a una sentencia proveniente de un juez estatal" ${ }^{\prime 9}$. Así, en el arbitraje existe una delegación de jurisdicción por parte del Estado a los árbitros, y, eventualmente, a los directores de los centros.

Asimismo, nuestro Código Orgánico de la Función Judicial en su art. 17 prescribe:

La administración de justicia por la Función Judicial es un servicio público, básico y fundamental del Estado, por el cual coadyuva a que se cumpla el deber de respetar y hacer respetar los derechos garantizados por la Constitución, los instrumentos internacionales de derechos humanos vigentes y las leyes.

El arbitraje, la mediación y otros medios alternativos de solución de conflictos establecidos por la ley, constituyen una forma de este servicio público, al igual que las funciones de justicia que en los pueblos indígenas ejercen sus autoridades ${ }^{50}$.

A través de este artículo, el arbitraje está siendo asimilado a la administración de justicia que realiza la Función Judicial.

En los Estados Unidos, se ha asemejado las funciones de las instituciones arbitrales a las de los jueces, y por ello se les ha aplicado la inmunidad absoluta a los centros, junto con todo su personal ${ }^{51}$.

49. F. GonZÁlez de Cossío, Sobre la Naturaleza Jurídica del Arbitraje: Homenaje a Don Raúl Medina Mora, p. 14, <goo.gl/rqxhA5>.

50. Código Orgánico de la Función Judicial, Art. 17, RO Sup. No. 544 de 09/03/2009.

51. M. RASMUSSEN, "Overextending Immunity: Arbitral Institutional Liability in the United States, England, and France", Fordham International Law Journal, No. 26 (6), 2002, p. 1840. 
In Ruberstein v. Otterbourg, the Civil Court of the City of New York granted immunity to the AAA, holding that the same immunity that protects arbitrators should be extended to arbitral institutions because they are quasijudicial organizations and immunity is increasingly being extended to them ${ }^{52}$.

Adicionalmente, en el caso Corey c. New York Stock Exchange, Corey demandó a la NYSE, institución que administró su controversia, por ocasionarle daños y perjuicios al haber actuado supuestamente en conspiración con el demandado en el arbitraje para vulnerar sus derechos. La Corte de Apelaciones de los Estados Unidos rechazó su pretensión porque consideró que, dada la naturaleza de las funciones de la institución arbitral, similares a las de un juez, gozaba de inmunidad ${ }^{53}$.

Sin embargo, este no es el caso de nuestro ordenamiento jurídico, pues no todas las actuaciones de la institución arbitral son jurisdiccionales. En Ecuador, solamente ciertas actuaciones de los directores de los centros de arbitraje pueden considerarse jurisdiccionales.

Por jurisdicción se entiende la facultad de administrar justicia, función pública encomendada a un órgano del Estado, que tiene por fin la realización o declaración del derecho mediante la actuación de la ley a casos concretos" ${ }^{\prime \prime 4}$. De acuerdo con nuestro ordenamiento jurídico este poder de administrar justicia solamente se ejerce por las personas designadas por la ley.

Para ejercer las funciones de calificación de la demanda ${ }^{55}$, ordenar la citación ${ }^{56}$ y resolver sobre la recusación de la demanda ${ }^{57}$, la Ley de Arbitraje y Mediación señala específicamente a los directores de la institución arbitral.

52. Ídem, p. 1845.

53. Corte de Apelaciones de los Estados Unidos para el Sexto Circuito, Corey c. New York Stock Exchange, $02 / 11 / 1982$.

54. H. Devis Echandía, Nociones Generales de Derecho Procesal Civil, Temis, 2009, p. 77.

55. Código Orgánico General de Procesos (COGEP), Art. 121, RO Sup. No. 506, 22/05/2015.

56. COGEP, N. 55, Art. 53.

57. COGEP, N. 55, Art. 23. 
En particular, la etapa pre-arbitral aunque sea conducida por los directores de los centros de arbitraje, es objeto de estricta regulación por parte de la ley, que como se ha visto proyecta en ella un conjunto de normas imperativas que no pueden dejar de ser aplicadas por aquéllos. Esta fase inicial está compuesta por una serie de actos de carácter procesal, a los que se adicionan otros de naturaleza puramente material $u$ operativa, necesarios unos y otros para la conformación ulterior del Tribunal. En este tramo preliminar tienen lugar actos tan significativos como el de la admisión o rechazo de la solicitud de convocatoria al Tribunal de Arbitramento, el traslado y la contestación de la demanda arbitral ${ }^{58}$.

Entonces, como el Estado es quien permite la existencia del arbitraje y delega a los árbitros la jurisdicción ${ }^{59}$, lo mismo sucede con los directores del centro, a quienes les ha delegado ciertas facultades jurisdiccionales.

[E]n este estadio al director del Centro de Arbitraje incumbe ejercer poderes procesales que traslucen una clara e indubitable función pública como son los relacionados con las diligencias de notificación, admisión y rechazo de la solicitud de convocatoria, decisión de los recursos de reposición, conducción de la audiencia de conciliación etc. (...). 7. No es posible negar la importancia jurídica y procesal de la etapa pre-arbitral, dado que si bien en ella no se decide la controversia, si se hace patente el ejercicio de una función pública que debe cumplirse conforme a un procedimiento legal vinculante tanto para el Centro como para las personas convocadas. Pese a que en esta etapa no se decide la controversia, la garantía del debido proceso y el derecho de defensa pueden resultar comprometidos cuando se violan los preceptos legales que la gobiernan $^{60}$.

Asimismo, la Corte Constitucional de Colombia ha fallado:

\footnotetext{
58. Corte Constitucional de la República de Colombia, Sentencia SU-600, 18/08/1999, fundamento 6, $<$ http://www.corteconstitucional.gov.co/relatoria/1999/SU600-99.htm>.

59. F. GonZÁlez de Cossío, El Arbitraje y la Judicatura, Editorial Porrúa, 2007, p. 150.

60. Corte Constitucional de la República de Colombia, N. 58, fundamentos 6 y 7.
} 
[L]a llamada etapa prearbitral, a cargo del director del Centro de Arbitraje, tiene no sólo gran importancia sino que además las funciones del director y del centro son de gran trascendencia. Así, le corresponde entre otras cosas, recibir la solicitud de convocatoria del tribunal de arbitramento, aceptar o rechazarla, y si es el caso, correr traslado de ella, y recepcionar su contestación, las excepciones previas o de mérito y la contrademanda, si la hubiere. Igualmente deberá llevar a cabo una audiencia de conciliación y conformar el tribunal ${ }^{61}$.

Existen varios argumentos para sustentar esta potestad jurisdiccional. En primer lugar, en los arbitrajes ad hoc todas estas funciones son responsabilidad del tribunal arbitral.

Un primer argumento a favor de que los actos del director del Centro de Arbitraje son de índole jurisdiccional, radica en que los arbitrajes independientes esas mismas atribuciones son ejercidas por él o los árbitros, sin que exista discusión alguna en cuanto a que dichas actuaciones se las realiza en ejercicio de facultades de índole jurisdiccional, razón por la cual no se comprendería el porqué de la naturaleza de esos mismos actos mutaría cuando se trate de un arbitraje administrado ${ }^{62}$.

El segundo argumento es que estas potestades son ejercidas normalmente por jueces en la justicia ordinaria.

Un segundo argumento que debe considerarse a favor de la tesis de que los actos del Director del Centro de Arbitraje son jurisdiccionales, es que al tratarse de procesos ordinarios, son actuaciones que le corresponden al juez y que inclusive se encuentran expresamente reguladas en nuestro Código de Procedimiento Civil, como por ejemplo, la calificación de la demanda, la convocatoria a una diligencia conciliatoria, la citación con la demanda, y ni qué decir del pronunciamiento respecto a una recusación ${ }^{63}$.

61. Corte Constitucional de la República de Colombia, Sentencia C-1038/02, 28/11/2002, fundamento 12, $<$ http://corteconstitucional.gov.co/relatoria/2002/C-1038-02.htm>.

62. J. F. Guerrero del Pozo, “¿Caben las medidas cautelares constitucionales en contra de un proceso arbitral?”, Revista Ecuatoriana de Arbitraje, No. 3, 2011, p. 121.

63. Ibídem. 
En este mismo sentido, las funciones de notificar en un arbitraje ya han sido consideradas jurisdiccionales en cortes de otros países. Por ejemplo, en el caso Ezra Austern c. The Chicago Board Options Exchange, Inc. la Corte de Apelaciones de los Estados Unidos para el Segundo Circuito sostuvo que la notificación a las partes sobre las audiencias del arbitraje es de naturaleza judicial ${ }^{64}$.

Lo mismo sucede con la citación. "Síguese por tanto, que etimológicamente, la notificación es género y la citación y el emplazamiento, especies; la primera significa hacer saber judicialmente, la segunda, hacer saber, con llamamiento para realizar un acto" 65 . Así, al ser una especie de notificación, la citación también tendría naturaleza jurisdiccional. Más aún, si con la citación se da inicio a la relación procesal ${ }^{66}$ y se da a conocer al demandado el contenido de la demanda.

Finalmente, lo propio ha sido concluido para la recusación. En el caso Jason et Al c. American Arbitration Association la Corte Distrital de los Estados Unidos para Luisiana resolvió que la resolución sobre la descalificación de un árbitro luego de un proceso de recusación implicaba el ejercicio de una función similar a la de los jueces ${ }^{67}$.

El tercer argumento a favor de la naturaleza jurisdiccional de las funciones del director tiene que ver con que las decisiones que se toman en la fase prearbitral tienen una vinculación directa con el arbitraje, por lo que también deben ser jurisdiccionales. Solo por ello se explica que se encuentren desarrolladas en el Código Orgánico General de Procesos.

La Corte considera que en el presente caso, [se puede] concluir que gran parte de las funciones desarrolladas por los centros de arbitramento en la fase prearbitral son de naturaleza judicial. De un lado, desde el punto de vista formal, en

64. Corte de Apelaciones de los Estados Unidos para el Segundo Circuito, Ezra Austern c. The Chicago Board Options Exchange, 15/03/1990.

65. Corte Suprema de Justicia de Ecuador, Segunda Sala de lo Civil y Mercantil, 26/04/2000.

66. Ibídem.

67. Corte Distrital de los Estados Unidos para Luisiana, Jason et al. v. American Arbitration Association, $23 / 05 / 2002$. 
esa fase, si bien no se decide directamente el fondo de la controversia, si se toman decisiones y se llevan a cabo trámites que tienen una vinculación directa con el proceso arbitral, que es de naturaleza judicial. Por ende, y como bien lo destaca la jurisprudencia del Consejo de Estado, esa etapa se encuentra indisolublemente ligada con un proceso judicial, y por ello se entiende que su naturaleza es también judicial. Por ello, se encuentra regulada por el estatuto procesal civil ${ }^{68}$.

\section{Adicionalmente,}

[D]esde el punto de vista material, las decisiones tomadas en esa fase prearbitral tienen consecuencias importantes en el acceso a la justicia arbitral, pues corresponde al director del centro de arbitramento, entre otras cosas, decidir sobre la admisibilidad de la solicitud de convocatoria del tribunal de arbitramento.

Conforme a lo anterior, la Corte concluye que la fase prearbitral tiene una naturaleza jurisdiccional, por las siguientes razones: (i) puede implicar limitaciones al acceso a la administración de justicia; (ii) está destinada a impulsar el proceso arbitral, que es de naturaleza jurisdiccional, y (iii) en su fondo y forma está sometida a lo previsto en el estatuto procesal civil para los procesos judiciales ${ }^{69}$.

Finalmente, el último argumento versa sobre que la ausencia o nulidad de estas actuaciones puede acarrear la nulidad de todo el proceso, como es el caso de la citación de la demanda ${ }^{70}$.

Así, concluimos que el director del centro de arbitraje ejerce ciertas funciones jurisdiccionales, establecidas en la ley. Estas serían la calificación de la demanda, la citación, la resolución de la recusación y las notificaciones de actuaciones procesales durante la etapa pre arbitral.

68. Corte Constitucional de la República de Colombia, N. 61, fundamento 18.

69. Ibídem

70. LAM, N. 23, Art. 31. 


\section{LA ReSPONSABILIDAd DEL DiRECTOR DEL CENTRO EN EJERCICIO DE SUS FUNCIONES JURISDICCIONALES}

En el civil law está reconocida la responsabilidad de los jueces y su antecedente data desde la época del Imperio Romano. En el Digesto se estableció que "el juez hace suyo el pleito cuando, con dolo malo sentencia en fraude de la ley pues el juez debe tener la equidad ante sus ojos (aequitatem ante oculos habere debet judex)" ${ }^{\prime 71}$. Este principio fue luego recogido en España en el Fuero Juzgo, el Fuero Real y las Siete Partidas ${ }^{72}$. Asimismo, fue recogido por el Código de Napoleón ${ }^{73}$.

Por el contrario, en el common law se ha reconocido la inmunidad de los jueces en el ejercicio de sus funciones.

En efecto, ya en Yates v. Lansing el juez Kent declaró que: "en toda ocasión que sometemos a los tribunales de la tierra a la degradación de la prosecución privada, limitamos su independencia y destruimos su autoridad". En la misma dirección poco después se señalaría que de no existir esta inmunidad tuteladora de la autoridad judicial "ningún ser humano, más que un mendigo o tonto sería juez" (Miller v. Hope) y más tarde el juez Field declararía que "resulta un principio general de suprema importancia para la apropiada administración de justicia que un funcionario judicial resulte, en ejercicio de la autoridad que le ha sido conferida, libre para actuar conforme a sus propias convicciones, sin aprensión por las consecuencias personales que pudieran derivar para él. La responsabilidad a efectos de responder frente a cada uno que se pudiera sentir agraviado por la acción del juez, resultaría inconsistente con tal libertad, y destruiría la independencia sin la cual ninguna judicatura puede ser ni útil ni respetable" (Bradley v. Fisher) ${ }^{74}$.

Pero ni siquiera en los Estados Unidos esta inmunidad es cien por ciento garantizada.

71. Ulpiano, Digesto, Libro V, Título I, Ley 15, párr. 1.

72. A. H. Rizzo Romano, "Responsabilidad Civil de los jueces y funcionarios judiciales. El punto de vista de un juez”, Responsabilidad Civil. Doctrinas Esenciales. 1936-2007, La Ley, 2007, p. 1540.

73. Ídem, p. 1541.

74. A. Dalmacio Andrada, "Responsabilidad de los magistrados judiciales. Derecho Argentino". Responsabilidad Civil. Doctrinas Esenciales. 1936-2007, La Ley, 2007, p. 1554. 
Even though judicial immunity is considered absolute in the United States, courts have allowed parties to sue judges in certain narrow circumstances. Where judges have acted with a complete lack of jurisdiction, parties have been able to sue for malicious prosecution and abuse of process. Also, judges are not immune for non-judicial acts that are administrative or ministerial in nature ${ }^{75}$.

Nuestro ordenamiento jurídico se aparta de la inmunidad y del sistema del common law y reconoce expresamente la posibilidad de que los jueces sean responsables por sus actuaciones. Esto se evidencia en la siguiente norma constitucional.

Art. 172.- Las juezas y jueces administrarán justicia con sujeción a la Constitución, a los instrumentos internacionales de derechos humanos y a la ley.

Las servidoras y servidores judiciales, que incluyen a juezas y jueces, y los otros operadores de justicia, aplicarán el principio de la debida diligencia en los procesos de administración de justicia.

Las juezas y jueces serán responsables por el perjuicio que se cause a las partes por retardo, negligencia, denegación de justicia o quebrantamiento de la ley ${ }^{76}$.

Asimismo, de acuerdo con la parte final del Art. 15 del Código Orgánico de la Función Judicial "[1]as juezas y jueces serán responsables por el perjuicio que se cause a las partes por retardo injustificado, negligencia, denegación de justicia o quebrantamiento de la ley, de conformidad con las previsiones de la Constitución y la ley"77. Dado que mediante la ley se establecen potestades jurisdiccionales para los directores, ellos también serían responsables por el retardo injustificado, la negligencia, la denegación de justicia o el quebrantamiento de ley.

75. "Aunque la inmunidad judicial se considera absoluta en los Estados Unidos, los tribunales han permitido a las partes demandar a los jueces en ciertas circunstancias limitadas. Cuando los jueces han actuado con total incompetencia, las partes han podido demandar por mala fe y abuso de proceso. Además, los jueces no son inmunes a los actos no judiciales de naturaleza administrativa o ministerial". Traducción libre. M. RASMussen, N. 51, p. 1842.

76. Constitución de la República del Ecuador, Art. 172, RO No. 449, 20/10/2008.

77. Código Orgánico de la Función Judicial, N. 50, Art. 15. 
Debemos tener en cuenta que además de que el director del centro cometa una de las conductas anteriores, deben necesariamente cumplirse los demás requisitos de la responsabilidad civil, que son el daño, la culpa o dolo, y el nexo causal, y no debe existir ningún eximente de responsabilidad.

[Los] supuestos de la legislación son casos de obligaciones legales, que generan responsabilidad extracontractual. Al no existir, como se verá, vínculo contractual alguno entre el magistrado o funcionario judicial presuntamente responsable del perjuicio causado y el damnificado, será en este último espectro, es decir, el de la responsabilidad extracontractual, en que se regirá la responsabilidad civil de los magistrados y funcionarios judiciales ${ }^{78}$.

Pasaremos a analizar los casos en los que respondería el director de la institución arbitral.

\subsection{Retardo injustificado}

El deber de no retardar injustificadamente la resolución de una controversia se encuentra en el artículo 128 numeral 5 del Código Orgánico de la Función Judicial ${ }^{79}$. Asimismo, el principio de celeridad se encuentra consagrado en dicho cuerpo normativo.

Art. 20.- Principio de celeridad.- La administración de justicia será rápida y oportuna, tanto en la tramitación y resolución de la causa, como en la ejecución de lo decidido. Por lo tanto, en todas las materias, una vez iniciado un proceso, las juezas y jueces están obligados a proseguir el trámite dentro de los términos legales, sin esperar petición de parte, salvo los casos en que la ley disponga lo contrario.

El retardo injustificado en la administración de justicia, imputable a las juezas, jueces y demás servidoras y servidores de la Función Judicial y auxiliares de la justicia, será sancionado de conformidad con la ley ${ }^{80}$.

78. G. S. TAWIL, La responsabilidad del Estado y de los magistrados y funcionarios judiciales por el mal funcionamiento de la administración de justicia. Depalma, 1993, pp. 166 y 167.

79. Código Orgánico de la Función Judicial, N. 50, Art. 128(5).

80. Código Orgánico de la Función Judicial. N. 50, Art. 20. 
De este supuesto se desprende que el retardo debe ser injustificado para demostrar responsabilidad. Así, en casos en los que han existido eximentes de responsabilidad, como lo son el caso fortuito o la fuerza mayor, no generan el deber de indemnizar a los jueces, y en nuestro caso, al director del centro.

Las obligaciones que mencionamos como jurisdiccionales que son la citación y la notificación de las actuaciones procesales del tribunal arbitral, la calificación de la demanda, la resolución de una recusación, todas pueden ser retardadas injustificadamente por el director. Éste sería uno de los supuestos en los que podría demandarse al director del centro, siempre que se cumplan con los demás requisitos para que proceda la responsabilidad extracontractual.

\subsection{Negligencia}

"La negligencia es el descuido con que el agente realiza sus actividades" $^{\prime 81}$. La negligencia es una especie de culpa ${ }^{82}$ e implica "no tomar las debidas precauciones sea en actos excepcionales, ora en los de la vida ordinaria" 83 .

La negligencia aparece cuando el sujeto omite la realización de un acto que habría evitado el resultado dañoso. Es aquella omisión más o menos voluntaria pero consciente de la diligencia que hubiere correspondido hacer de modo tal que no llegara a producir el efecto perjudicial. En suma, la negligencia manifestada del autor del hecho lesivo se produce cuando habiendo motivos para prever el perjuicio que acontecería, no actúa con suficiente diligencia para evitarlo ${ }^{84}$.

En nuestro caso, un actuar negligente por parte de los directores del centro podría darse, por ejemplo, en no realizar un aná-

81. J. Tamayo Jaramillo, Tratado de Responsabilidad Civil, Tomo I, Legis, 2008, p. 227.

82. Ibídem.

83. L. JimÉnez Asúa. Citado por J. TAmayo Jaramillo, Tratado de Responsabilidad Civil, Tomo I, Legis, 2008, p. 228.

84. Corte Suprema de Justicia de Ecuador, Primera Sala de lo Civil y Mercantil, Comité "Delfina Torres Vda. de Concha" c. PetroEcuador y otros, 29/10/2002. 
lisis cuidadoso de la información que las partes y el árbitro entregan para el caso en que deba resolverse una recusación. También podría darse el caso de que no hubo un seguimiento al hecho de que en efecto se haya dado una citación o notificación; o revisar los requisitos de admisibilidad de la ley de una forma descuidada que impliquen un perjuicio para el actor porque se le deniegue trámite a una demanda que sí cumple los requisitos; o para el demandado si no se le citó con la demanda.

Como mencionamos anteriormente, es necesario que se cumplan todos los requisitos de la responsabilidad civil extracontractual para que se genere el deber de indemnizar por un descuido en el ejercicio de las funciones del director de la institución arbitral.

\subsection{Denegación de justicia}

Respecto de [la] denegación de justicia, este tipo de infracción se produce cuándo (sic) él (sic) juzgador no cumple con su obligación jurisdiccional, negándose a administrar justicia, pues tanto la Constitución y la ley, establecen que las juezas y jueces fallarán en las causas que sean puestas en su conocimiento y no se abstendrán de administrar justicia, ni aún bajo el pretexto de falta de ley ${ }^{85}$.

En conjunto con esta definición, debe tenerse en cuenta que un principio de nuestra Constitución es el no sacrificar la justicia por formalidades ${ }^{86}$. Además, el deber de administrar justicia se encuentra consagrado en el Art. 28 del Código Orgánico de la Función Judicial, que les prohíbe excusarse de resolver por ausencia de norma y oscuridad de la ley ${ }^{87}$.

Asimismo, debe tomarse en cuenta que la denegación de justicia es un concepto amplio y vago, que en principio abarca mu-

85. Corte Nacional de Justicia, Sala de lo Civil, Mercantil y Familia, Caso Geovanny Petrilli D'Agostini c. Alfredo Oramas González y otros, 01/06/2010.

86. Constitución de la República del Ecuador, N. 76, Art. 169.

87. Código Orgánico de la Función Judicial, N. 50, Art. 28. 
chos supuestos, por lo que debe interpretarse y estudiarse caso por caso ${ }^{88}$. Un caso de denegación de justicia claro es la falta de un fallo definitivo sobre la materia puesta a conocimiento de una autoridad, que resuelve ciertos puntos pero que no se pronuncia sobre lo principal de la controversia y ello debe afectar severamente el derecho de alguna de las partes ${ }^{89}$. Esto se daría por ejemplo, si el director del centro se niega a dar trámite a la demanda por algún requisito que no se encuentre en la legislación.

\subsection{Quebrantamiento de ley}

Finalmente, tenemos el caso de quebrantamiento de ley, que se explica por sí sola. El deber de fallar conforme al ordenamiento jurídico se encuentra prescrito por el artículo 28 del Código Orgánico de la Función Judicial ${ }^{90}$. Lo único que debe agregarse es que no cualquier quebrantamiento a la ley es suficiente, debe existir un perjuicio real, de conformidad con las normas generales de la responsabilidad civil. Un ejemplo de ello podría ser resolver la recusación en transgresión al principio de contradicción o al debido proceso.

\section{Conclusiones}

El arbitraje institucional fue creado para que los árbitros puedan resolver los temas jurisdiccionales y las partes no se vean obligadas a colaborar entre sí cuando justamente se encuentran en disputa. Por ello, la labor del centro es esencialmente administrativa.

La responsabilidad de las instituciones arbitrales es contractual, tal como hemos explicado anteriormente. Así, en caso de incumplimiento de las obligaciones del centro, es posible reclamar una indemnización por daños y perjuicios por el incumpli-

88. J. Paulsson, Denial of Justice in International Law, Cambridge University Press, 2005, p. 68.

89. Corte Interamericana de Derechos Humanos, Caso Salvador Chiriboga c. Ecuador, 03/03/2011.

90. Código Orgánico de la Función Judicial, N. 50, Art. 28. 
miento del CAA, junto con el cumplimiento o la resolución del contrato.

Sin embargo, la responsabilidad de los directores del centro en el ejercicio de sus funciones jurisdiccionales es extracontractual. Dichas funciones son la calificación, citación de la demanda y la reconvención, la resolución de las recusaciones, la convocatoria a la audiencia de mediación, y la notificación de diligencias procesales antes de que se posesione el tribunal arbitral. Como se trata del ejercicio de jurisdicción, los directores responden de la misma forma que los jueces y se limita al retardo injustificado, negligencia, denegación de justicia o quebrantamiento de ley. 